\title{
Flashes in ashes
}

\section{Allan Piper considers the biggest and most promising of five new energy projects sponsored by the International Energy Agency (IEA).}

$\mathbf{T}_{\mathrm{H}}^{\mathrm{H}}$ HE opening earlier this week of a London headquarters for a new National Coal Board (NCB) subsidiary will probably cause no more than a passing ripple in the whirlpool of international energy affairs. Few people can have heard of NCB (IEA Services), and fewer still will know what it represents. But its potential long-term impact on the global energy scene should not be underrated.

In the rush to develop new energy technologies, coal, once in decline as a major energy source, has assumed a renewed importance. Under its Ten Year Plan the NCB aims to boost UK coal production by $15 \%$ over the next decade. The US plans to expand its coal industry by a factor of three. Elsewhere-in Europe, the Soviet Union and Australia-similar production drives are getting under way.

But bringing coal out of the ground is one thing; how best to use it is another. The value of coal lies not only in its potential as a fuel. It aiso shows massive promise as a chemical feedsstock, and as a source of premium grade hydrocarbons. Much research is needed-and it is here that NCB (IEA Services) comes in. Set up by the NCB last Novermber, it will look after coal research in Britain for the IEA. Five projects, costing an overall $£ 15$ million, have already come its way. Four of them are relatively modest: costing an annual $£ 1$ million or so, they involve merely the collection of information for the next five years, keeping the ten nations involved abreast of economic and technological developments.

The fifth project is by far the largest and most promising. It involves the design, construction and operation of an 85 MW fluidised bed combustor on an old NCB site at Grimethorpe in Yorkshire. Jointly financed by Britain, the USA and West Germany, the combustor is expected to cost $£ 6$ million to build, and a little over $£ 500,000$ a year to run during its eight-year life as an IEA test bed-a total of around $£ 10.5$ million.

With so much attention being focused in Britain on nuclear power and North Sea oil resources, the true significance of Grimethorpe is likely to pass unnoticed. In the past, fluidised combustion-an elegant technique for burning fuels efficiently, economically and cleanly-has been sadly undersupported in relation to its technological potential. But Grimethorpe marks a turning point. Through the Depart- ment of Energy (DEN), which will provide $66 \%$ of the cost of Britain's share of the project (the rest will come from the NCB), the UK Government is providing solid backing for the first time.

There are, moreover, preliminary discussions under way between the NCB and leading industrial companies on the early introduction of a $60 \mathrm{MW}$ commercial, prototype in addition to the Grimethorpe test bed. Such a step should be technologically possible, and might have been taken already had funds been available. As it is, success in the present talks, and subsequent government approval, could see the first British prototype operating within five years.

\section{Bed of ashes}

Fluidised combustors boast advantages that cry out for commercial exploitation. Because they are more compact and efficient than conventional burners, capital construction costs and running costs are lower. They operate at lower temperatures, forming less clinker and slag and thus lowering maintainance costs. They offer operational flexibility: multifuelled combustors can be designed to burn coal, oil and gas, with switchover times measured only in hours. Thus, while they might usefully exploit fluctuations in different fuel prices, they can aiso remain immune to temporary shortages of particular fuel types. Moreover, by burning extremely low grade coals they could help stretch economic reserves, reducing overall coal production costs.

These benefits spring from the way fluidised combustion works. The underlying principle is startlingly simple. In a fluidised combustor the proportional amount of air involved in fuel burning far exceeds that found in conventional burners. During combustion, tiny fuel particles are continually fed into a bed of fine mineral ash, maintaining a proportion of 1 part fuel to around 200 parts ash. At the same time, an even flow of air is passed upwards through the fuel bed, causing it to act like a turbulent fluid-hence the name fluidised combustion.

As the fuel particles mill around in the airstream they do not stick together because of the low combustion temperature. Consequently they burn extremely thoroughly, distributing heat more efficiently than under ordinary burning conditions. The heat can be utilised either by passing cooling tubes through the fuel bed, or by using more air than is needed to maintain turbulence, and extracting it from the top of the combustion chamber.

The potential range of application is enormous. As electrical power generators, fluidised combustors might usefully be considered by the Central Electricity Generating Board (CEGB), now busily closing dozens of small, urban coal- and oil-fired plants that could perhaps be converted to complement the nuclear baseload. In industry, fluidised combustors can be used to run small boilers and drying kilns, and pressurised plant can drive gas turbines. They can also be designed as incinerators for sewage sludge, organic and chemical wastes, and everyday municipal rubbish.

With every application the waste heat is easily harnessed. District heating is an obvious area for development here. The DEN, now devoting greater attention to the potential of combined heat and power schemes, is unlikely to overlook this bonus.

The environmental advantages will not be overlooked either. In fluidised combustion the production of $\mathrm{SO}_{2}$ and nitrogen oxides is easily controlled and minimised. This is because burning temperatures are in the relatively low range of $750-950^{\circ} \mathrm{C}$. On the one hand, this is too cool for the production of most oxides of nitrogen; on the other, it is perfect for the harmless combination of $\mathrm{SO}_{2}$ with ground limestone placed in the ash bed.

\section{Dusty record}

Against that background the poor record of support for research and development (R\&D) seems surprising. The CEGB, with potentially so much to gain, withdrew almost entirely from the

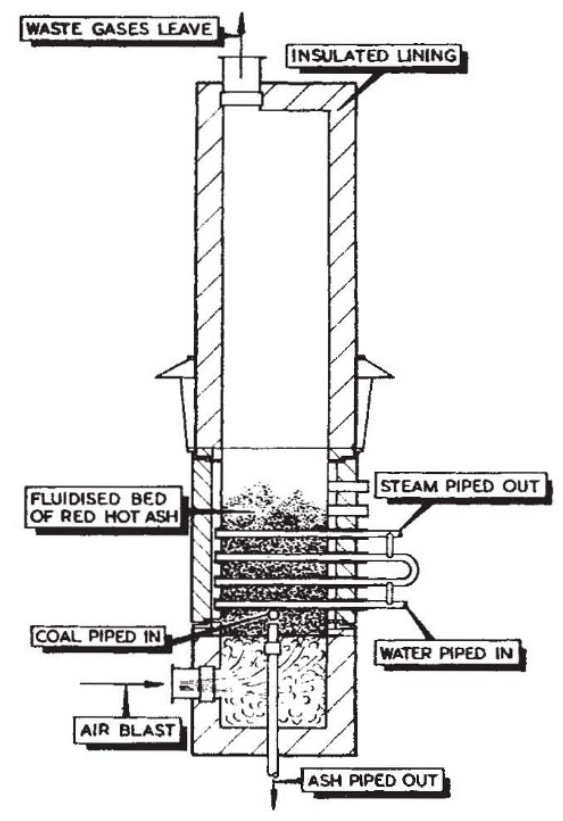

Fluidised bed combustor 
scene soon after launching pioneering work in the middle $1950 \mathrm{~s}$, turning instead to the greater promise then offered by nuclear power and oil. It has since remained involved only in an advisory capacity. Throughout the 1960s the NCB carried the R\&D effort virtually alone. The UK Government did not become directly involved until about five years ago, and then only in a minor way with the formation of Combustion Systems Limited (CSL), a tripartite research organisation involving the National Research Development Corporation, the NCB and British Petroleum (BP). The private sector has since shown increasing interest.

The Grimethorpe test bed is not the first in Britain. Progress made by the NCB during the 1960 s led to the construction and successful operation of several small experimental rigs at the British Coal Utilisation Research Association (BCURA) in Surrey, and the Coal Research Establishment (CRE) in Gloucestershire. The BP Research Centre at Sunbury on Thames has also been the centre of recent applied research by CSL. Two small commercial plants are already operating in Britain, one of them at Renfrew in Scotland, where the enginering company Babcock and Wilcox runs a 13.5 MW fluidised combustion boiler. The other is used as a grass dryer by an enterprising Lancashire farming family.

Grimethorpe will not represent the first attempt at international collaboration on fluidisation combustion. Work at BCURA in 1970 and 1971 on environmental benefits was sponsored jointly by the NCB and the US Environmental Protection Agency. Over the past five years, following the withdrawal of NCB funding for BCURA, studies on pressurised plant have been supported entirely by the US Office of Coal Research. CSL facilities are currently used by the US Electrical Power Research Institute and the National Swedish Environment Protection Agency, together with many independent commercial organisations. CSL projects are themselves partially supported by grants from the European Coal and Steel Community. With more effort at both national and international level, development might have passed beyond its present point, but the funding was not available.

Pcrhaps the greatest single setback came in 1971 when the NCB, having decided to stop carrying the R\&D burden on its own, failed to win government backing for a planned $20 \mathrm{MW}$ demonstration steam boiler. Only $£ 2$ million was involved, and the Advisory Council on Research and Development (then under the Ministry of Power) had just reported favourably on fluidised combustion; initial design studies for the project had been sup-

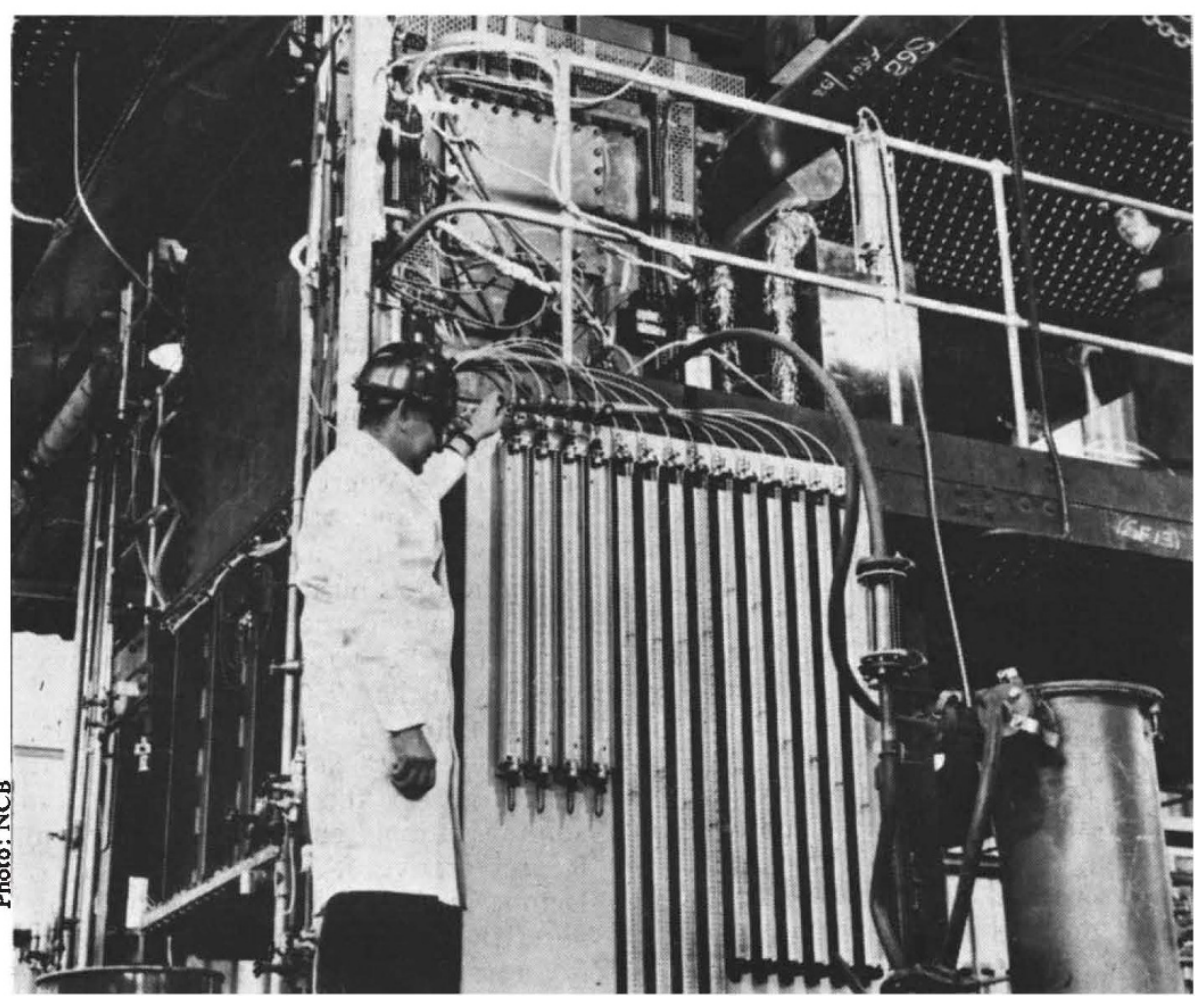

Experimental fluidised bed combustor at Coal Research Establishment

ported by government grants totalling $£ 200,000$.

But the Tory government had only recently come to power, the CEGB, riding the tide of nuclear expansion, was indifferent about the idea and had itself declined to give support, and even the NCB commitment was less than total. Furthermore, export prospects did not look rosy: the US administration for the most part still spurned fluidised combustion, ironically preferring to place massive emphasis on the development of pollution control units for conventional burners.

\section{Dead ahead}

Following that setback it was arguably only through the formation of CSL that Britain maintained its technological lead. Not until the coal industry examination of 1974 involving the government, the NCB and mining unions-did fluidised combustion become identified as a priority area for R\&D, along with pyrolosis and liquefaction. The decision to support Grimethorpe with DEN funds acknowledged that finding. Orders for hardware should go to UK, US or West German contractors within the next 12 months.

So fluidised combustion looks set to come into its own. In the UK, apart from Grimethorpe and the planned prototype, CSI is actively considering a $66 \mathrm{MW}$ combined heat and power pressurised gas turbine. The British Steel Corporation may well introduce a small unit into its River Dunn works in Yorkshire. The General Electric Company has declared an interest in the proposed British prototype. And a new joint company, Babcock-CSL has been established as a design and export base.

In the US too, R\&D is pressing ahead independently of the IEA project. Work on a $\$ 15$ million pressurised test bed is due to start near Chicago this autumn, sponsored by the US Energy Research and Development Administration. A lot is at stake. While coal makes up $90 \%$ of recoverable fossil fuel researves in the US, much of it has an extremely high sulphur content. Fluidised combustion offers the opportunity to exploit these reserves without violating anti-pollution standards.

The enthusiasm is matched in Europe, in spirit if not with financial backing. Although only West Germany will share the running costs of Grimethorpe with Britain and the US, the other seven member nations of the IEA Working Party on Coal Technology will have access to data. France, alone among the major European nations, has remained cool, but her absence poses no problems.

Fluidised combustion could have tremendous relevance to the future world energy scene. Few now question the crucial importance of nuclear power. And few will argue with the NCB's suggestion that coal's greatest notential lies in pyrolysis and liquefaction. But where coal must be used as a fuel, fluidised combustion looks like becoming the cheapest, cleanest, and most efficient way of using it. As one NCB board member has put it, the greatest innovations are yet to come 